\title{
Análise das Práticas de uma Clínica-Escola de Psicologia: Potências e Desafios Contemporâneos
}

\author{
Bárbara Morais Fam ${ }^{1}$ \\ ${ }^{1}$ Pontifícia Universidade Católica de Minas Gerais, \\ MG, Brasil.
}

\author{
João Leite Ferreira Neto ${ }^{1}$ \\ ${ }^{1}$ Pontifícia Universidade Católica de Minas Gerais, \\ MG, Brasil.
}

Resumo: Este estudo buscou identificar as potências e os desafios da experiência formativa em uma clínica-escola de Psicologia, investigando como essa instituição atende as demandas da formação dos alunos no contexto contemporâneo. Realizou-se um estudo de caso na clínicaescola da PUC Minas. Os procedimentos metodológicos contemplaram uma triangulação de métodos, envolvendo as seguintes estratégias: pesquisa documental, observação participante, questionários e entrevistas. As contribuições de Michel Foucault inspiraram o processo de produção e análise dos dados. Os resultados mostraram que, embora a clínica estudada seja um espaço de aprendizado potente e privilegiado para se atender às demandas formativas atuais por competências, plurais, éticas, que articulam teoria-prática e ensino-pesquisa-extensão -, muitos desafios perpassam em seu cotidiano, dificultando operacionalizações. Na instituição em questão ainda existem dificuldades para se superar um enfoque conteudista, a busca por especializações precoces e a baixa conexão entre teoria e prática, o que inibe articulações mais precisas e práticas menos fragmentadas. A maioria dos entrevistados apontou como desafio a falta de uma articulação mais bem estruturada, efetiva e continuada extramuros, com a rede de saúde pública, e intramuros, com os demais serviços da Universidade. Conclui-se que a clínica-escola é muito bem-vista e avaliada, mas seu cotidiano evidencia controvérsias diversas, o que indica a necessidade de que suas práticas sejam repensadas, principalmente devido às novas configurações sociais.

Palavras-chave: Clínica-escola, Formação do Psicólogo, Diretrizes Curriculares Nacionais, Ensino da Psicologia, Michel Foucault. 


\title{
Analysis of Practices of a Psychology Training-Clinic: Current Potentials and Challenges
}

\begin{abstract}
This study aimed to identify the potentials and challenges of the training experience in a psychology training clinic, investigating how this institution meets the demands of students' training in the current context. A case study was carried out at PUC Minas training-clinic. The methodological procedures included a triangulation of methods, involving the following strategies: documentary research, participant observation, surveys and interviews. Michel Foucault's contributions inspired the process of producing and analyzing data. Although the training clinic studied, is a powerful and privileged learning space to face the current training demands - for competencies, plural, ethical, that articulate both theory-practice and teaching-researchextension - many challenges pervade in its daily activities, and thus make operationalizations difficult. In this institution there are still difficulties in overcoming: the exclusive focus on content, the search for early specializations, and the low connection between theory and practice, and this inhibits more precise articulations and less fragmented practices. Most of the interviewees pointed out the lack of a more structured, effective and continuous articulation outside the walls, with the public health network, and intramural, with the other University services. Finally, the schoolclinic is very well regarded and evaluated, but its daily life evidences diverse controversies, which indicates the need for its practices to be rethought, mainly due to the new social configurations.
\end{abstract}

Keywords: Psychology Training Clinic, Psychologist Training, Curriculum Guidelines, Psychology Education, Michel Foucault.

\section{Análisis de Las Prácticas de una Clínica-Escuela de Psicología: Potencias y Desafíos Cotemporáneos}

Resumen: Ese estudio buscó identificar las potencias y los retos de la experiencia formativa en una clínica escuela de psicología, investigando cómo esa institución atiende las demandas de formación de los alumnos en el contexto contemporáneo. Fue realizado un estudio de caso en la clínica-escuela de la universidad PUC Minas. Los procedimientos metodológicos contemplaron una triangulación de métodos, involucrando las siguientes estrategias: investigación documental, observación participante, encuestas y entrevistas. Las contribuciones de Michael Foucault inspiraron el proceso de producción y análisis de datos. Se concluyó que, aunque la clínica-escuela estudiada sea un espacio de aprendizaje de gran alcance y privilegiado para atender a las demandas formativas actuales - por competencia, general, plural, ética, que articulan la teoría práctica y la enseñanza-investigación-extensión - muchos retos transcurren en su cotidiano, lo que entorpece las operacionalizaciones. En la institución en cuestión, todavía hay dificultades para superar la enseñanza tradicional, la busca por especialización precoz y la poca conexión entre teoría y práctica, lo que inhibe articulaciones más exactas y prácticas menos fragmentadas. La mayoría de los entrevistados indicó como reto la falta de una articulación mejor estructurada, efectiva y continua con, extramuros, la red pública de salud y, intramuros, con los otros servicios de la universidad. Se concluye que la clínica-escuela es muy bien vista y evaluada, pero su cotidiano evidencia controversias diversas, lo que indica la necesidad de que sus prácticas sean repensadas, principalmente debido a las nuevas configuraciones sociales.

Palabras clave: Clínica-Escuela, Formación del Psicólogo, Directrices Curriculares Nacionales, Enseñanza de la Psicología, Michel Foucault. 
As clínicas-escolas ocupam um lugar central na formação oferecida nas instituições de ensino superior no Brasil. Ali ocorrem atividades práticas de estágio e supervisões, além da coordenação dos estágios externos, obrigatórios ou não (Conselho Federal de Psicologia, 2013, p. 14). Tendo em vista sua importância, entende-se que há necessidade de revisão periódica de suas práticas, visando otimizar seu funcionamento para o aluno e para o cliente. Embora nos últimos 20 anos tenha ocorrido um aumento do interesse pela caracterização da clientela e descrição do funcionamento das clínicas-escolas, ainda existem poucos estudos científicos sobre a temática (Oliveira et al., 2014). A pesquisa aqui apresentada objetivou preencher essa lacuna e identificar as potências e os desafios da experiência formativa em uma clínica-escola de Psicologia, a fim de investigar em que medida essa instituição atende as demandas da formação dos alunos no contexto contemporâneo.

Amaral et al. (2012) realizaram um levantamento bibliográfico a fim de identificar e analisar as publicações relativas às clínicas-escolas de Psicologia nos últimos 10 anos. Os pesquisadores encontraram 45 trabalhos disponibilizados on-line, o que consideraram um número pequeno. Entre as publicações ressaltam-se as referentes à representação social do psicólogo que trabalha nessas instituições e o papel do supervisor de estágio (quatro), à descrição da clientela (sete), aos serviços diferenciados e abordagens (27), ao atendimento ao aluno (uma), à triagem (duas) e ao atendimento infantil (quatro). Foram encontrados também trabalhos que relataram a prática psicológica em diversos contextos, assim como orientação profissional, atendimento a queixa escolar e com população específica.

É consenso entre os pesquisadores do tema que um dos maiores desafios enfrentados pelas clínicas-escolas é o fato de serem instituições que prestam serviços concomitantemente à formação discente e à comunidade. Essa condição é desafiadora, pois as demandas de uma dimensão acabam interferindo na outra. Alguns atravessamentos institucionais, como o calendário acadêmico e a limitação do tempo de supervisão, por exemplo, são inevitáveis. Tratam-se de condições institucionais que devem ser levadas em consideração e pensadas como características das clínicas-escolas que se organizam a partir e em função dos cursos. Neste sentido, a pesquisa de Boeckel et al. (2010) sugere a compreensão do papel das clínicas-escolas como sendo de ferramenta de formação e ação social, que contemple o contexto de inserção do aluno e que tem um compromisso ético para com as demandas socioculturais atuais. Como afirmam Poelman, Bedran, Barroso e Lasmar (2009, p. 46):

a Clínica não se pode reduzir a local de "prática", onde os alunos exercitem os métodos e técnicas ensinados no curso, para aprender a manejá-los mais adequadamente, nem se pode transformar em mais um "centro de saúde da comunidade", que acolhe os excluídos do atendimento pela rede dos serviços de saúde, em detrimento da formação do futuro psicólogo.

Essa dupla condição faz com que as clínicas-escolas pareçam locais privilegiados para a articulação entre teoria-prática e ensino-pesquisa-extensão. Marturano, Silvares e Oliveira (2014) defendem a interdependência entre as três dimensões (ensino-pesquisa-extensão) de uma clínica-escola, destacando a importância da pesquisa para o aprimoramento de práticas de atendimento à comunidade e práticas formativas do psicólogo. Já Araldi, Maraschin e Dihel (2014), em uma pesquisa com estudantes da graduação em Psicologia da Universidade Federal do Rio Grande do Sul (UFRGS) em estágio de ênfase, viram que há dificuldades para se conceber uma articulação efetiva entre teoria e prática. Essas dimensões ainda aparecem como registros diferentes e até opostos.

Estudos já mostraram, também, que as clínicas-escolas têm cumprido satisfatoriamente suas propostas de atendimento à comunidade. Honda $\mathrm{e}$ Yoshida (2012) realizaram uma pesquisa na qual objetivaram avaliar mudanças em pacientes atendidos em clínicas-escolas e compreender possíveis fatores que influenciam os resultados das psicoterapias. Os resultados sugerem o abrandamento dos sintomas psicopatológicos e progresso nos estágios de mudança. Arend e Motta (2014) pesquisaram como usuários que se encontravam na sala de espera da clínica-escola do Centro Universitário Franciscano - Rio Grande do Sul concebem a representação social da Psicologia e do psicólogo. Foi visto que, embora haja reconhecimento do trabalho realizado pelos estagiários, existem dificuldades dos usuários em estabelecer diferenças entre a Psicologia e o psicólogo: a ambos foi atribuída uma função assistencialista, de ajuda e de entendimento 
dos problemas de ordem psicológica. Diante disso, podemos pensar que os trabalhos nas clínica-escolas são benquistos pela comunidade, embora sejam associados às práticas assistencialistas.

Importa salientar que a história das clínicas-escolas no Brasil está vinculada à história dos cursos de Psicologia e da regulamentação da profissão de psicólogo. O antigo currículo mínimo, Parecer no 403/1962, lançado no dia 19 de dezembro de 1962 pelo Conselho Federal de Educação (CFE), era orientado por uma perspectiva conteudista, que trabalhava com aplicação de fundamentos teóricos, com acúmulo e assimilação de conhecimentos. No ano de 1996 foi criada uma comissão de especialistas para cada curso de graduação, em decorrência da Lei de Diretrizes e Bases de Educação (LDB) no 9.394 (1996), visando criar diretrizes curriculares nacionais, que substituíssem o modelo formativo do currículo mínimo. O modelo de formação passou a ser baseado em competências e habilidades essenciais nas situações de atuação profissional adquiridas através de um conjunto de experiências formativas.

Após quase sete anos de debates depois da promulgação da LDB, em 2004, uma nova regulamentação para a graduação em Psicologia emergiu com a Resolução no 8/2004. As Diretrizes Curriculares Nacionais (DCN) para os cursos de graduação em Psicologia nasceram com o objetivo de proporcionar orientações sobre princípios e procedimentos para o planejamento, implementação e avaliação do curso no Brasil. De acordo com a Associação Brasileira de Ensino de Psicologia (2013) as inovações trazidas com as Diretrizes de 2004 podem ser elencadas dessa forma: a inexistência da formação intermediária de bacharéis, tal como era feito nos cursos organizados com base no Currículo Mínimo; a existência de um núcleo comum no currículo de todos os cursos; a articulação de competências básicas e de eixos estruturantes; a inclusão de estágios básicos; o refinamento das propostas de estágios específicos e a inclusão de ênfases curriculares.

Apesar de algumas clínicas-escolas de Psicologia terem surgido bem antes das DCN, com a Lei no 4.119 de 1962, a qual determinava a organização de "servi- ços clínicos e de aplicação à educação e ao trabalho", a partir da aprovação das DCN as faculdades buscaram redesenhar seus currículos e práticas educacionais. O Art. 25 dessa Lei determina a instalação de um Serviço de Psicologia ${ }^{1}$ nas universidades, ressaltando como objetivos dos mesmos: "[...] responder às exigências para a formação do psicólogo, congruente com as competências que o curso objetiva desenvolver no aluno e a demandas de serviço psicológico da comunidade na qual está inserido" (Parecer No CNE/ CES 0062/2004, 2004). As clínicas-escolas então passaram a estruturar seus serviços nessas duas recomendações: ser congruente com as competências que o curso visa desenvolver no aluno e ofertar atendimento à comunidade na qual está inserida.

As DCN definem "competências" como os desempenhos e atuações requeridas do formado em Psicologia, que devem garantir ao profissional um domínio de alguns "conhecimentos psicológicos e a capacidade de utilizá-los em diferentes contextos que demandam a investigação, análise, avaliação, prevenção e atuação em processos psicológicos e psicossociais, e na promoção da qualidade de vida", conforme estipulado no Art. 8. (BRASIL, 2004, p. 2). Segundo Zarifian (2009, p. 137), a ideia de competência se define por três elementos complementares uns aos outros:

É a tomada de iniciativa e o assumir de responsabilidade do indivíduo sobre problemas e eventos que ele enfrenta em situações profissionais; É uma inteligência prática das situações, que se apoia em conhecimentos adquiridos e os transforma à medida que a diversidade das situações aumenta; É a faculdade de mobilizar redes de atores em volta das mesmas situações, de compartilhar desafios, de assumir áreas de responsabilidade.

Isso significa que a interseção de conhecimentos e habilidades profissionais instaurou um novo modelo formativo, em detrimento do modelo conteudista que vigorou por muito tempo. Nessa lógica não se trata de aprender a fazer, mas de saber o porquê se faz dessa

\footnotetext{
${ }^{1}$ Há um movimento no estado de São Paulo que visa à substituição do termo “clínica-escola” para "serviço-escola”, o que se deu a partir do $12^{\circ}$ Encontro de Clínicas-Escolas desse Estado, em 2004. Essa é uma tentativa de se acompanhar as discussões em torno do campo da clínica. A intenção é ressaltar as várias frentes de intervenção desses serviços, que vão além dos estritamente clínicos (Amaral et al., 2012). Sabemos que os estudos mais atuais têm usado essa terminologia, porém, isso ainda não é consenso entre outros locais no Brasil. Neste trabalho utilizou-se "clínica-escola", pois é o termo adotado na clínica universitária estudada.
} 
maneira e que ela não é a única possível. Além disso, nessa lógica o trabalhador deve compreender o processo de produção do trabalho, suas culturas e seus valores, havendo margem para autonomia e exigência de responsabilidade (Zarifian, 2009).

Alguns pesquisadores defendem que o modelo atual tem sido insuficiente para romper com o conservadorismo do qual a formação é herdeira, muito em função da lógica neoliberal embutida no modelo das competências (Lima, \& Souza, 2014; Bernardes, 2012; Yamamoto, 2012). A despeito disso, as DCN e o modelo por competências trouxeram avanços para a formação. Acredita-se que uma visão simplista que a julgue a partir do conceito de "neoliberal" não abrange a complexidade da questão. Como bem assinala Ferreira Neto (2011, p. 42): "se por um lado as Diretrizes têm um alinhamento claro com os princípios hegemônicos do mercado neoliberal (afinal, o que hoje consegue fugir completamente disso?), por outro, estabelecem uma relevante mudança na compreensão da formação".

Em seu estudo, Seixas (2014) defendeu que existem enormes discrepâncias entre o discurso formativo, os currículos dos cursos e o que se apresenta na prática. Os debates ético-políticos, representados pela defesa do "compromisso social da Psicologia" e pela "Psicologia crítica e reflexiva", permeiam maciçamente as discussões sobre formação. Mas, segundo o autor, os currículos continuam focados em áreas clássicas da Psicologia, a formação ainda é conteudista, a clínica ainda é preponderante e há pouquíssima inovação nas disciplinas. Já nos debates vinculados à prática profissional do psicólogo prevalece a defesa de uma formação generalista e de integração teoria-prática, porém, embora isso conste nos currículos, ainda não é uma realidade dos cursos. $\mathrm{E}$, por fim, no que tange aos debates em torno da formação acadêmico-científica, há defesa de pesquisas e do tripé ensino-pesquisa-extensão, mas esse tripé ainda aparece de maneira desarticulada nos cursos.

A partir das prescrições formativas que regem os cursos de Psicologia e, por consequência, as clínicas-escolas e entendendo as dificuldades que perpassam o cotidiano de trabalho, os objetivos específicos da pesquisa aqui descrita foram: apresentar as demandas formativas contemporâneas através de aspectos históricos da formação em Psicologia e das clínicas-escolas; conhecer a historicidade, as práticas e as relações de poder de uma clínica-escola de
Psicologia; e analisar a perspectiva de estagiários, supervisores e coordenadores sobre o processo formativo naquele espaço.

\section{Metodologia}

Para alcançar esses objetivos, foi realizado um estudo de caso na clínica-escola da Pontifícia Universidade Católica de Minas Gerais - PUC Minas, unidade Coração Eucarístico. Realizou-se uma pesquisa com triangulação de métodos, que contemplou tanto dados qualitativos quanto quantitativos. As estratégias metodológicas foram: análise dos principais documentos referentes à instituição, observação participante das atividades cotidianas da clínica, aplicação de questionários autopreenchíveis a 200 estagiários, entrevistas com quatro professores-supervisores e com a coordenação da clínica. A pesquisa foi aprovada por Comitê de Ética e Pesquisa (Registro $\left.\mathrm{n}^{\circ} 37672514.8 .0000 .5137\right)$ e em todas as fases os participantes assinaram um Termo de Consentimento Livre e Esclarecido (TCLE).

Decidiu-se realizar um estudo de caso uma vez que não tínhamos uma hipótese a priori a ser comprovada. Buscou-se identificar potências e desafios de modo exploratório e abrangente. O estudo de caso se mostrou adequado porque geralmente essa metodologia tem um propósito duplo: compreender de maneira abrangente o grupo estudado e desenvolver declarações teóricas a respeito de processos sociais (Becker, 1997). Para a realização de um estudo mais completo, valeu-se do que Flick (2009) denomina como "triangulação de métodos". A triangulação possibilita a abertura de diferentes perspectivas, promovendo mais qualidade na pesquisa.

Buscou-se, com inspiração em Foucault, conceber a clínica-escola como um dispositivo constituído por uma historicidade descontínua e não linear, por práticas discursivas e não discursivas e permeada por relações de poder-saber que produzem subjetivações. Procurou-se mapear a pluralidade de forças que concorrem ali e evitar as classificações binariamente, pois, para Foucault (1979), o que está em jogo em qualquer acontecimento são formas mutáveis de se exercer o poder, que se liga a configurações de saber, produzindo assim determinados processos de subjetivação.

Para Foucault (1979), ainda, um dispositivo está sempre inserido em um jogo de poder apoiado a configurações de saber, de processos de subjetivação e 
está, invariavelmente, ligado a uma historicidade não linear, obtendo assim funções estratégicas e sofrendo constantes variações e mudanças. Em suas palavras, um dispositivo consiste em:

[...] um conjunto decididamente heterogêneo que engloba discursos, instituições, organizações arquitetônicas, decisões regulamentares, leis, medidas administrativas, enunciados científicos, proposições filosóficas, morais, filantrópicas. Em suma, o dito e o não dito são os elementos do dispositivo. O dispositivo é a rede que se pode estabelecer entre estes elementos (Foucault, 1979, p. 244).

Em Foucault, as práticas discursivas e não discursivas são atravessadas pela historicidade, essa entendida de forma não linear, mas marcada por descontinuidades. Em torno do acontecimento singular analisado como processo, buscamos então construir, em nossa análise, o que Foucault (2003) denominou como "poliedro de inteligibilidade". Com isso, o autor tentou ressaltar a indefinição prévia do número de faces de uma prática, bem como seu caráter inconclusivo, o que faz com que tenhamos que proceder por "saturação progressiva" e "forçosamente inacabada".

A pesquisa não visou, portanto, buscar o que está por trás dessas questões, mas apontar seus paradoxos e mapear as forças antagônicas que perpassam e constituem a experiência formativa na clínica na contemporaneidade. As análises realizadas congregam, conjuntamente, as potencialidades e os desafios envoltos nessas demandas e na dimensão da formação no cotidiano da clínica.

Em primeiro lugar, foi feita uma análise documental para conhecer a história da instituição e suas práticas. Solicitou-se à coordenação e à secretaria o fornecimento de documentos que poderiam subsidiar o que se pesquisava. Os documentos analisados então foram: O projeto de implantação de um espaço físico próprio para a clínica, de 1989; O "Projeto Educacional do curso" no qual consta também o projeto educacional da clínica, de 2003; A atualização do projeto educacional do curso, de 2008 e os "Boletins informativos" dos últimos cinco anos e as publicações dos temas das "Jornadas da clínica" também dos últimos cinco anos, a saber: 2011, 2012, 2013, 2014 e 2015.
Após essa pesquisa documental foi realizada uma observação participante, já que depois da análise dos documentos já se podia ter uma ideia de como focar a observação e, além disso, as questões que surgissem poderiam ser esclarecidas nas futuras entrevistas. Com o aval da coordenação da clínica, a pesquisadora responsável observou o cotidiano do local a fim de conhecer de perto as relações que ali se estabelecem e como os atores institucionais lidam no dia a dia com as prescrições documentais. Para as observações, seguiu-se o que Flick (2009) propõe. Nos primeiros dias de ida ao campo, privilegiou-se uma observação descritiva: realizou-se um panorama geral da clínica criando condições para uma orientação do estudo. Nos demais dias a atenção à primeira fase foi mantida, mas avançou-se para a segunda, a observação focalizada: restringiu-se o olhar às questões da pesquisa.

A observação descritiva funcionou da seguinte maneira: primeiro, a pesquisadora observou um turno da manhã e um da noite por completo. A partir dessas observações, percebeu-se que os horários de maior pico estão situados entre 10h e 13h, bem como entre 16h e 19h. Cobriram-se então esses horários todos os dias durante uma semana. A pesquisadora circulava entre a área interna da clínica, onde pacientes e estagiários ficam; a sala de estagiários, espaço privilegiado para interação dos alunos; e secretaria. Conversava com os estagiários que estavam livres, questionando-os sobre o que tinham a dizer sobre a experiência naquela clínica-escola. Em um momento posterior, retornou à clínica para acompanhar supervisões de estágio, após negociação com a coordenação. Solicitou isso diretamente a cada professor. Acompanhou uma supervisão do $8^{\circ}$ período, uma do $9^{\circ}$ e uma do $10^{\circ}$. Nessa situação, a observação não foi participante. As observações foram anotadas em um pequeno caderno de campo e depois transcritas.

Finalizadas as observações participantes, iniciou-se a aplicação dos questionários, pois nesse momento já eram conhecidas as principais questões que emergiram a partir das falas espontâneas, o que orientou a construção do instrumento. A aplicação aconteceu no mês de junho, após acordo com a coordenação da clínica-escola. Nesse mês, questionários autopreenchíveis foram entregues pessoalmente a cada estagiário nas dependências da clínica, juntamente com um TCLE. Contudo, devido à interrupção do período de férias, as aplicações continuaram no mês de agosto, 
dessa vez em sala de aula, após permissão da coordenadora do curso de Psicologia. Na primeira etapa foram preenchidos 101 questionários e, na segunda 99, o que totalizou 200 questionários. Os questionários foram aplicados a todos os estagiários que já tinham feito estágio na clínica, independentemente se estavam fazendo no período da aplicação ou não. Enfrentaram-se dificuldades devido à ausência de alunos, o que fez com que o objetivo de contemplar todos os estagiários não pudesse ser cumprido.

Cumpre mencionar que, dos 200 estagiários que responderam o questionário, $6,5 \%$ estavam no sexto período, $29,5 \%$ no sétimo, $25 \%$ no oitavo, $21,5 \%$ no nono e $17,5 \%$ no décimo conforme Figura 1.

\section{Período dos Estagiários}

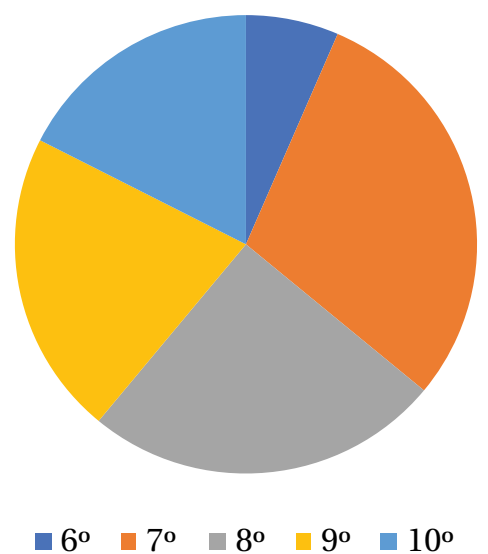

Fonte: Dados da pesquisa.

Figura 1 - Período dos estagiários

\section{Turno dos estagiários}

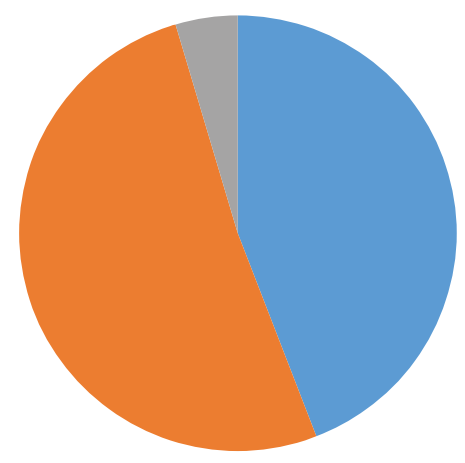

Manhã

Fonte: Dados da pesquisa.

Figura 2 - Turno dos estagiários
Dos estagiários, ainda, 44,2\% eram do turno da manhã, $51,3 \%$ da noite e $4,6 \%$ irregulares, como mostra a Figura 2.

$82,6 \%$ do sexo feminino e $17,4 \%$ do sexo masculino (Figura 3).

Conforme Figura 4, a maioria (60,7\%) tinha entre 20 e 24 anos, seguida por aqueles que tinham entre 25 a 34 anos (23\%), 35 a 44 (8,7\%); 45 a $546,1 \%$ e mais de $55(1,5 \%)$.

Supervisoras também foram entrevistadas. As entrevistas foram realizadas em momentos e locais distintos, sempre a cargo da disponibilidade e preferência das entrevistadas. Selecionaram-se supervisoras buscando a variedade das abordagens

\section{Sexo dos estagiários}

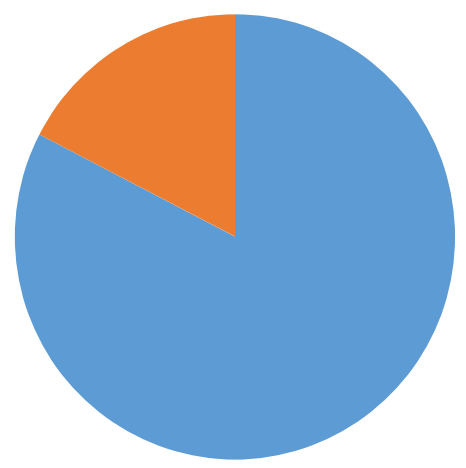

Feminino Masculino

Fonte: Dados da pesquisa.

Figura 3 - Sexo dos estagiários

Idade dos estagiários

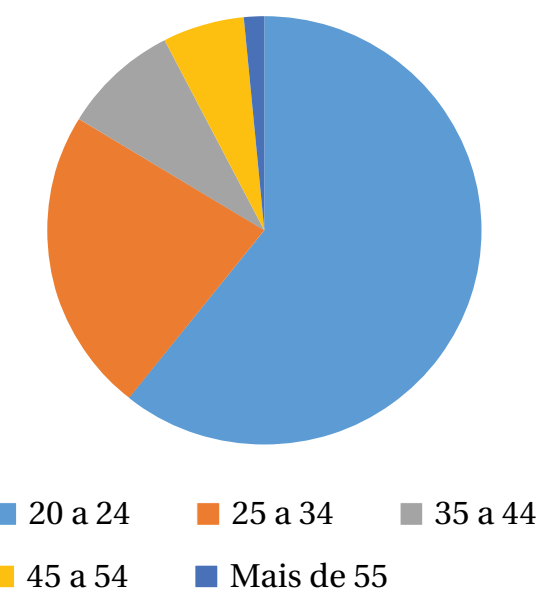

Fonte: Dados da pesquisa.

Figura 4 - Idade dos estagiários 
teórico-metodológicas oferecidas pela instituição, a saber: uma psicanalista, uma comportamental, uma sistêmica e uma humanista. As quatro supervisoras selecionadas eram mulheres e tinham muito tempo de vinculação à PUC Minas e à clínica-escola, uma delas desde a fundação do curso e recém-aposentada. Nenhuma delas tinha menos que vinte anos na universidade. Todas têm vasta experiência clínica e trabalham em consultório particular. A entrevista com a coordenadora foi a última a ser realizada, pois ela poderia esclarecer possíveis dúvidas quanto ao funcionamento institucional que não tivessem sido sanadas no decorrer da pesquisa.

Os dados das questões fechadas dos questionários foram analisados com o auxílio do programa estatístico SPSS. As análises dos dados qualitativos foram feitas com o auxílio do programa Atlas ti. O processo analítico, conforme mencionado, foi realizado a partir de uma inspiração foucaultiana e buscou apreender as diferentes forças que concorriam nas falas. Vale lembrar, com Ferreira Neto (2015, p. 419), que seguir esse caminho

[...] não se faz pela trilha preguiçosa da citação ou pela reprodução dos mesmos problemas enfrentados por Foucault, mas pela construção de nossos próprios problemas e instrumentos de pesquisa, sem abdicarmos do diálogo com métodos clássicos, na medida em que podem ser úteis à nossa pesquisa. Em suma, pelo trabalho diligente que se diferencia da colagem do autor e ao mesmo tempo nos modifica no processo da pesquisa.

Seguindo essas ideias, os temas mais frequentes que surgiram em todas as etapas da pesquisa foram sendo analisados. Constantemente retornava-se aos dados para que as análises de cada etapa fossem retroalimentadas umas nas outras. Foi um processo conjunto e concomitante, embora a produção dos dados tenha acontecido em momentos distintos. Por esse motivo, os resultados são apresentados de forma genérica. Na pesquisa, as análises estão descritas como "nós analíticos" que se formaram por meio da amarração das temáticas mais recorrentes em todas as etapas da pesquisa. Segue um apanhado geral dos resultados.

\section{Resultados}

As análises documentais revelaram que as principais demandas formativas estão contempladas nos documentos que regem a clínica-escola. O projeto educacional do curso estudado, reverberando as premissas das DCN, frisa a importância de se ter uma formação por competências "a ênfase não está mais no que se deve ensinar, mas no que se deve aprender [...] A tônica está na construção de competências e habilidades, mais que na mera transmissão de conhecimentos" (Pontifícia Universidade Católica de Minas Gerais, 2003, p. 37). O projeto educacional também preza por uma formação generalista, pois coloca que os alunos devem: "ter competências e habilidades necessárias para atuar independente do campo em que venha a trabalhar" (Pontifícia Universidade Católica de Minas Gerais, 2003). Vale lembrar que a necessidade de uma formação generalista aparece nas DCN associada a uma exigência do mercado de trabalho, pela ampliação dos campos de atuação dos psicólogos. O curso da PUC Minas optou por uma formação com duas ênfases: "Clínica e Psicologia" e "Organizações e Sociedade”. Sobre a ênfase clínica: "a ênfase clínica acrescenta à formação do psicólogo já desenvolvida na PUC Minas conteúdos que possibilitam sua atuação para além da clínica privada" (Pontifícia Universidade Católica de Minas Gerais, 2003).

A pesquisa mostrou que a clínica-escola, sendo um espaço de aprendizagem diferente da sala de aula, permite aos alunos experiências clínicas diversas e inéditas, contribuindo para uma formação calcada nas DCN. Como afirmou uma supervisora durante a entrevista, a clínica é um espaço em que o aluno "tem a experiência da vivência da profissão, com todas as questões que ela traz, do inesperado, do particular de cada caso, e ao mesmo tempo assegura a ele uma assistência, um acompanhamento do supervisor". A maioria dos alunos, em uma pergunta do questionário, disse achar que as experiências na clínica-escola irão contribuir para o trabalho profissional futuro, conforme mostra a Tabela.

Um estagiário escreveu no questionário:

[...] acredito que as experiências na clínica vão contribuir para minha atuação profissional porque faço estágio aqui desde o sexto período e a prática e os conhecimentos adquiridos são de grande importância para a formação. $\mathrm{O}$ aluno se forma com mais confiança para exercer a clínica. 
Tabela

Contribuição das experiências na clínica para a atuação profissional.

\begin{tabular}{lcccc}
\hline & Frequência & Percentual (\%) & \% válido & \% acumulado \\
\hline Muito & 126 & 63,0 & 64,3 & 64,3 \\
Sim & 64 & 32,0 & 32,7 & 96,9 \\
Mais ou menos & 5 & 2,5 & 2,6 & 99,5 \\
Pouco & 1 & 0,5 & 0,5 & 100,0 \\
Total & 196 & 98,0 & 100,0 & \\
Não respondeu & 4 & 2,0 & & \\
Total & 200 & 100,0 & & \\
\hline
\end{tabular}

Fonte: Questionário aplicado aos estagiários.

A observação participante, contudo, mostrou que os estagiários se preocupam mais com o "como fazer" do que com o porquê fazer, acreditando que exista um único modo verdadeiro e correto de se atuar na clínica. Em conversas com estagiários, muitos falaram da "ansiedade" e "nervosismo" que sentem junto à prática e da "insegurança" que os permeia, principalmente quando ocorrem situações que fogem ao esperado. Uma estagiária disse: "temos dúvidas de coisas bobas, de como fazer, de coisas práticas, isso é pouco discutido".

A pesquisa revelou, também, que há supervalorização da teoria adotada, em detrimento de outros aspectos. A preocupação com as distinções teóricas apareceu constantemente nas falas dos estagiários. Durante a observação participante, presenciei uma conversa entre duas estagiárias: "neurose, psicose, perversão... eu quero entender o que ela está querendo dizer!" A outra disse: "isso é psicanálise. Humanista não acredita em estrutura”. Apesar de a maioria dos supervisores considerar que a formação na abordagem na graduação é insuficiente e valorizar uma formação generalista, essa preocupação apareceu também na fala das professoras entrevistadas. Uma delas explicou:

[...] muitas vezes o psicólogo adota uma teoria e faz dela a única verdade. Isso é complicado e repercute na formação dos alunos, porque eles se sentem confusos. Eles não podem gostar de duas ao mesmo tempo. Eles têm que fazer uma escolha às vezes muito absoluta sem estarem preparados para isso.

A análise dos questionários indicou que a grande maioria dos estagiários considera que a principal potência da clínica é proporcionar contato com a prática. Alguns alunos disseram gostar da clínica, pois é o local privilegiado para que aconteça uma relação entre teoria e prática. Muitos, ao citarem essa relação, demonstraram existir dificuldade em se realizar uma articulação entre as duas dimensões. Os alunos, por vezes, escreveram que a teoria é mais importante ou falaram da necessidade de "colocar" teoria na prática. O "contato com a prática" apareceu mais como uma "aplicação" do que como uma "articulação". Essas respostas dos questionários ilustram isso: "é uma prática muito importante para aplicar conhecimentos teóricos". Outro escreveu: "através delas [das experiências na clínica] podemos ver na prática o que aprendemos na teoria sob supervisão", ou ainda: "tive a oportunidade de praticar a teoria". Alguns fizeram o caminho inverso. Questionaram a supervalorização teórica e defenderam uma construção teórica a partir da prática: "a teoria sem a prática se torna muito pobre"; "É na prática que se tem contato com a realidade".

Apenas alguns estagiários apontaram uma articulação teórico-prática: "as experiências me ajudaram a aprofundar a teoria e articular com a prática". $\mathrm{Na}$ fala de uma supervisora a teoria apareceu a partir de uma concepção por competências, que se ajusta e se constrói a partir da prática:

porque o aluno às vezes expressa isso [a dificuldade de integração] com a pergunta: 'mas professora, afinal, qual teoria que é a certa?' [...] Você não tem que ter só a teoria, você tem que ajustar a teoria àquele encontro que você tem com a pessoa. É um desafio. 
A pesquisa mostrou que há, cada vez mais, tendência para ocupação de diferentes campos de atuação, mas que ainda existem conflitos na convivência entre eles. $\mathrm{O}$ trabalho em consultório particular e em outros campos aparecem dicotomizados, o que instaura, inclusive, tensões internas. Isso dificulta uma formação generalista, preconizada pelos documentos, e acaba empurrando os alunos para restrições precoces, através da antecipação de uma abordagem teórica a ser escolhida durante a graduação. Os estágios em diferentes campos aparecem desarticulados e isolados em si mesmos, não havendo diálogo, mas tensionamentos: "eu, por exemplo, não conseguiria trabalhar com Recursos Humanos (RH). Não sei nada. Teria que fazer especialização" (Estagiária).

Um estagiário, em uma conversa que tivemos durante a observação participante, levantou uma questão importante: durante as supervisões, os professores devem orientar os casos ou os alunos? Segundo ele, alguns orientam mais o aluno em suas dúvidas e dificuldades, enquanto outros focam na orientação do caso, das questões dos pacientes. Para esse estagiário especificamente, o supervisor deve orientar o aluno. Isso implica privilegiar a via da formação e não a do atendimento pelo qual o aluno e a instituição assumem responsabilidade. Em casos mais sérios, talvez haja necessidade de se escutar melhor o caso. Uma supervisora contou que atualmente, diante da gravidade dos casos, tem ido a alguns atendimentos, junto com o estagiário, o que, a seu ver, tem gerado resultados positivos:

[...] isso teve um efeito esclarecedor sobre a questão do caso e sobre a minha orientação para determinados pontos do caso. Eu não fazia isso antes, mas me fizeram ver que eu deixaria tanto o caso quanto o estagiário muito desamparados se eu não tivesse ali presente em algumas situações [...] a dimensão tão nova da manifestação clínica de certos sintomas requer que se mude a configuração até da supervisão (Supervisora).

E isso leva a outro aspecto muito importante revelado pela pesquisa: que, diante das transformações contemporâneas, os casos que chegam à clínica têm sido cada vez mais graves. É absolutamente necessário investigar se a clínica está preparada para atender essas novas configurações sintomáticas e qual a melhor forma de fazer isso. Segundo a coordenadora as crianças estão chegando "com sintomas psicóticos tomando 'ritalina'. Tem acontecido muito! Mas muito! [...] Eu nunca vi tanta criança com caso grave. E não é só suspeita de autismo e psicose não, é depressão, autoextermínio". Ela explicou:

[...] casos de clientes que a gente recebe que aparentemente são casos de pouca complexidade, mas que durante os atendimentos eles vão revelando uma maior complexidade e a gente tem que se posicionar... tem que buscar ajuda na rede para esses casos... tentativas de suicídio, depressões graves... casos em que a gente não sustenta sozinho, a gente tem que estar numa rede... casos de abusos.

No que tange à esfera da formação, que é o foco deste estudo, cabe questionar a configuração das práticas de supervisão, o acompanhamento dos alunos, a condução dos casos e, de maneira mais ampla, o trabalho da clínica-escola, fundada em uma época em que a clientela era diferente: "A clientela era outra, os projetos de estágio eram outros, os modos de fazer clínica eram outros. [...] Então muda a configuração dos casos, muda também a forma de trabalhar" (Supervisora).

Fica então uma pergunta: há algo desatualizado nesse modelo de clínica-escola? A maioria dos entrevistados apontou que a falta de uma articulação mais bem estruturada, efetiva e continuada com a rede de saúde pública é um dos maiores desafios atuais. Hoje em dia, quando é necessário que um caso tenha mais de uma frente de intervenção, a busca deve ser feita pelos supervisores e pelos alunos. Não há um caminho institucionalizado, o que acaba dificultando essas iniciativas tão necessárias, ainda mais frente aos sintomas mais graves que estão aparecendo. Ou seja, atualmente essas são iniciativas pontuais de cada professor-supervisor com seus estagiários, conforme explicou uma supervisora:

por exemplo, a gente está tendo muitos casos de pessoas em surto, tentativa de suicídio... é uma tarefa muito grande porque o supervisor tem que lutar com o aluno para acionar o psiquiatra da rede, encaminhar o caso, providenciar medicação, a clínica não tem isso pronto. 
Um estagiário, durante a fase de observação, disse que há necessidade de a clínica realizar encaminhamentos para outras áreas e que sente falta de um contato permanente com um psiquiatra, por exemplo. Segundo ele, a clínica só atende encaminhamentos de outros cursos, ela deveria realizar encaminhamentos também: "às vezes é necessário. Eu nunca vi isso acontecer". Ou seja, a falta de articulação não ocorre somente extramuros, com a rede pública, mas também intramuros com os serviços oferecidos no campus por outros cursos. Mas vale ponderar que a própria estrutura da Universidade, organizada a partir de campos disciplinares, favorece esse estado de coisas.

O resultado disso é "solidão", conforme apareceu na fala da coordenadora e das professoras entrevistadas: "é muito solitário. Por quê? Porque a clínica até hoje não conseguiu fazer um caminho institucional... a gente não consegue institucionalizar". A fala de outra supervisora também mostra isso:

[...] os casos chegam à clínica por encaminhamento, no entanto, não se tem uma rede que vai se construindo a partir de cada caso como um modelo de trabalho para todos os casos. Eventualmente isso acontece, quando é do interesse do supervisor fazer essa rede, mas não é ainda um modelo que toda a clínica, todos os casos se beneficiam dele. (Supervisora).

A mesma supervisora frisou bastante essa questão e defendeu a necessidade de que haja mais discussão acerca da clínica em rede, sobre "como avançar na inserção da clínica universitária na rede”. Ela explicou que a regional onde a clínica está localizada é a mais populosa da cidade e que existem diversos dispositivos na região, como o Centro de Referência em Saúde Mental (Cersam) Noroeste, o Centro de Referência em Saúde Mental Infantojuvenil (Cersami), escolas e clínicas de saúde. Mas que essas instituições apenas encaminham casos para a clínica, não há construção de rede para cada caso

[...] até hoje, não se avançou muito na construção da rede necessária para cada caso, contando não só com a clínica, mas com essas outras instituições do entorno que seriam, a meu ver, corresponsáveis por esses casos, sobretudo considerando esses novos sintomas que requer do psicólogo um trabalho em rede, um trabalho interdisciplinar, multidisciplinar (Supervisora).

Outra entrevistada ressalvou que a integração com a rede é valorizada pela clínica, ainda que não haja um movimento concreto buscando sua viabilização. Assim, para ela, o grande desafio é "ter mais recursos, ter mais prática, agilizar mais os processos...”. A coordenadora argumentou que há anos as coordenações tentam essa articulação: "nós já fizemos seminários, já convidamos pessoas da rede, mas sem sucesso". Para ela, "o apoio da rede é instável, depende de quem atende o telefone, não há uma política da rede conversando". De acordo com seu ponto de vista, a prefeitura teria uma rede fechada, que não conversa com outros lugares de apoio, fenômeno que a literatura chama de insulamento burocrático (Nunes, 2010).

Segundo a coordenadora, os casos que escapam à rede acabam indo para a clínica-escola, o que também contribui para a mudança no perfil da clientela: "porque antes era clientela típica da baixa complexidade e agora nós estamos recebendo a média e a alta, porque eles não têm lugar na rede". Além disso, os casos que chegam à clínica têm sido mais graves frente às transformações da sociedade. Como afirma Morin (2003, p. 13), os problemas e a realidade têm sim se tornado mais "polidisciplinares, transversais, multidimensionais, transnacionais, globais, planetários". Logo, modelos disciplinares fragmentados e compartimentados estão cada vez mais inadequados.

Vale explicar que a conduta da clínica diante de casos mais graves, de urgência, é chamar a família para levar o paciente para um lugar adequado: "a gente chama a família, não deixa ele sair daqui em surto. A gente liga, faz a rede rapidamente por telefone, e encaminha. Tem caso que dá certo, tem caso que não dá" (Coordenadora). A coordenadora afirmou que eles têm buscado articulações internas e ressaltou a importância da articulação com a extensão "porque eu acho que é uma terceira via em que a gente pode criar metodologias, então a gente tem buscado muitas parcerias com a extensão. Ainda são pequenas parcerias".

Portanto, embora a clínica-escola seja um local de formação privilegiado para se articular ensino-pesquisa-extensão, ainda existem desafios a serem superados para que isso efetivamente ocorra. Uma supervisora deixou claro que a conexão entre essas três dimensões ainda é um ponto a ser trabalhado: “eu 
penso que é necessário que uma clínica-escola faça essa articulação: do serviço prestado, da dimensão da extensão e do ensino. Acho que se isso não se conecta - e está desconectado - compromete a formação" (Supervisora). Outra entrevistada lembrou que um dos maiores desafios da clínica está na falta de integração da própria formação, que ainda é constituída por disciplinas compartimentadas e fragmentadas.

\section{Discussão}

No que tange à dimensão da formação, de modo geral, os resultados apresentados mostraram que a avaliação que os alunos fazem acerca das experiências de atendimento e de supervisão nas clínicas-escolas são muito positivas: $96,4 \%$ disseram que suas experiências foram satisfatórias (ótimas, muito boas ou boas). A pesquisa mostrou que as principais demandas formativas estão contempladas nos documentos que regem o curso e a clínica-escola: baseiam-se oficialmente no modelo de competências; buscam ser generalistas, embora o currículo seja dividido em ênfases compartimentalizadas; valorizam integrações e o rompimento com visões dicotômicas e fragmentadas. No entanto, o cotidiano da clínica-escola evidencia controvérsias diversas, que mostram a dificuldade de se conceber uma formação tal qual a preconizada nos documentos institucionais.

A pesquisa mostrou que as raízes conteudistas da formação prevalecem e aparecem como pontos centrais na dimensão formativa da clínica-escola estudada, consistindo em uma das maiores preocupações dos alunos. Eles ficam presos às orientações das supervisões e imaginam que existe apenas um fazer correto, e não um conjunto de alternativas, que cada um, a seu estilo, deverá encontrar. Um exemplo disso ocorreu em uma supervisão do oitavo período. Os alunos queixavam-se de não conseguir encerrar os atendimentos no horário, de não saber o que falar no fim do atendimento. Para a supervisora aquela era uma questão muito simples: "simplesmente levantar e ir se despedindo (levantando-se da cadeira)". Isso vai na contramão das prescrições institucionais e do modelo por competências. Afinal, nessa lógica: "não basta aprender a fazer, adquirindo os automatismos inerentes a um dado exercício profissional, mas saber o porquê está fazendo de uma maneira e não de outra e que existem várias formas de se fazer algo, não apenas uma" (Zarifian, 2009).
Acredita-se que o modelo de competências, muito criticado por atender a uma sociedade que centraliza a performance para o trabalho, trouxe avanços com relação ao modelo conteudista. Com base nas ideias de Deleuze (1992), vê-se que essa lógica se aplica às necessidades e características da sociedade de controle. Trata-se agora de produzir um sujeito capaz de responder às demandas flexíveis do mercado, que seja capaz de agir frente às situações-problema, cada vez mais complexas, e responder por seus atos, assumindo responsabilidade e mobilizando a rede de atores em sua volta. Concorda-se com Cury e Ferreira Neto (2014) quando afirmam que a mudança para o modelo de competências envolverá alterações da cultura formativa, o que leva tempo e esforço.

Outro ponto de reflexão importante refere-se à necessidade de uma integração efetiva entre teoria e prática. Nesse aspecto, a pesquisa mostrou resultados que já haviam sido contemplados por Araldi, Maraschin e Dihel (2014), segundo os quais ainda existem dificuldades para se conceber essa articulação. Considera-se que uma integração efetiva não concebe a prática somente como pragmática e operativa, sem diálogo teórico, nem a teoria como fundamento absoluto das práticas. Uma teoria deve servir às situações, não se sobressaindo às experiências proporcionadas pelos encontros. Afinal, como lembra Deleuze em sua conversa com Foucault (Foucault, 1979, p. 71):

[...] uma teoria é como uma caixa de ferramentas. Nada tem a ver com o significante. É preciso que sirva, é preciso que funcione. E não para si mesma. Se não há pessoas para utilizá-la, a começar pelo próprio teórico que deixa então de ser teórico, é que ela não vale nada ou que o momento ainda não chegou. Não se refaz uma teoria, fazem-se outras; há outras a serem feitas.

A pesquisa indicou que para as supervisoras entrevistadas os alunos aprendem muito com a vivência que têm na clínica-escola, independentemente do contexto em que desejam trabalhar depois de se formarem. Alguns estagiários também defenderam que os projetos de estágios disponíveis darão subsídios para que possam atuar em qualquer contexto:

[...] é uma oportunidade única dada ao aluno enquanto futuro profissional de estar em contato com o contexto clínico. Por mais que a clínica 
não seja um objetivo a curto prazo, penso que a experiência que tenho adquirido aqui me servirá em toda minha vida profissional (Estagiário).

Ao lado disso, há uma forte tensão entre o modelo de consultório particular e o dos outros campos de atuação. A clínica aparece dicotomizada, tanto na voz de professoras quanto de alunos, que são mais críticos com relação à clínica convencional. Uma das supervisoras entrevistadas acredita que está acontecendo um "esvaziamento" do consultório particular: "é lógico que tem outros espaços para os psicólogos, né?! As políticas públicas, a rede... são espaços que devem ser ocupados também, mas não precisa esvaziar o consultório". Ela disse que os alunos estão vivenciando essa realidade: "Eu vejo isso lá na PUC. O aluno desanimado com o consultório, achando que isso é uma clínica ultrapassada... não é! Não é!”. E isso apareceu na fala dos alunos. Alguns disseram que o consultório é uma prática atrasada e falaram sobre a dificuldade financeira para se abrir um hoje em dia: "entrei na Psicologia para isso, mas hoje a clínica está em declínio, muita gente fechando e indo trabalhar com RH, que é o que dá dinheiro" (Estagiário). De qualquer modo, existem tensionamentos entre a formação para os diferentes campos de atuação. É importante lembrar que a combinação de duas ou mais inserções é a marca da profissão, abrangendo $65 \%$ dos psicólogos (Costa et al., 2012).

Diante disso, concorda-se com Bernardes (2012) quando diz que é preciso conceber o conceito de ênfase de maneira mais ampla, abrangente e não excludente. $\mathrm{O}$ aluno não precisa, mesmo optando por alguma ênfase, excluir completamente as outras. A formação generalista deve prezar para que o psicólogo seja capaz de agir em diversas e diferentes situações profissionais, e não apenas transitar por várias áreas e/ou abordagens durante o curso:

[...] argumento que a formação generalista não pode ser reduzida a um transitar, em pouco tempo, entre áreas ou campos de atuação em Psicologia; não pode ser confundida com a agregação da experiência dos estudantes por meio de um pot-pourri de diferentes áreas ou campos de atuação em Psicologia. Tampouco pode ser confundida com pluralidade ou diversidade (Bernardes, 2012, p. 223).

Na visão de Bernardes (2012) há o desafio de transcender a lógica da racionalidade técnica implí- cita na Psicologia aplicada; transcender a lógica da especialização precoce e trazer para o debate o perfil generalista na formação e, assim, ressignificar o conceito de competência. O processo formativo deve cuidar para que o aluno possa não somente transitar, durante a formação acadêmica, entre diferentes níveis, formas de apreensão e intervenção na realidade, mas construir novos posicionamentos tendo como referencial os acontecimentos que o mobilizam a intervir. Os cursos devem ter uma perspectiva mais ampla na qual o psicólogo faça parte de uma rede e se comprometa com a sociedade ao trabalhar na promoção da saúde da comunidade, para que esteja preparado para o trabalho multi e interdisciplinar, questione e busque respostas, tal como defendem Arend e Motta (2014).

Os dados da pesquisa mostraram que a principal questão se refere à necessidade de se repensar o modelo de clínica-escola a partir das novas configurações sociais e do perfil dos sintomas da clientela atendida: "eu lembro que não havia o uso de termo suicídio, nunca estudei isso na graduação, isso não era tema... depressões graves... e hoje no consultório eu estou tendo que me formar nisso" (Coordenadora). Uma articulação mais bem estruturada, efetiva e continuada com a rede de saúde pública e com a própria Universidade se coloca como demanda urgente. Afinal, como lembrou uma supervisora:

[...] qualquer outra instituição de prestação de serviço da universidade tem que estar inserida na assistência pública, nos serviços públicos, né, fazendo rede com esses outros serviços e na rede interna, porque temos outras clínicas, da fonoaudiologia, da fisioterapia, que nem sempre se faz essa rede interna, e os casos são casos que vêm aqui, que vão lá na clínica de fono, que transitam (Supervisora).

Ou seja, trabalhar em rede tornou-se fundamental. Vale ressalvar que isso não está contemplado nos documentos analisados e aparece nas falas como uma questão recente. As entrevistas sugeriram que os casos que escapam à rede estão indo para a clínica-escola e que, em geral, são casos graves. Entram aqui os atravessamentos institucionais, que acabam por dificultar o tratamento de casos de urgência. Como disse a coordenadora: 
é uma clínica de ensino, pesquisa e extensão. Né?! Por ser de ensino, e tenho o atravessamento de calendário, das matrículas, dos alunos... isso fragiliza qualquer tentativa de a gente construir aqui um serviço mais sólido em relação às urgências (Coordenadora).

Diante desse empasse, constata-se que se deve repensar o modelo de clínica-escola atual e evidencia-se a urgência de que ela seja integrada à rede de saúde pública e outros serviços da Universidade.

Sintetizam-se assim as forças contraditórias da experiência formativa no dispositivo, clínica-escola, estudado: uma das principais potencialidades do curso de Psicologia da PUC Minas são as práticas de estágio e a clínica-escola aparece como um lugar privilegiado para que essas práticas ocorram. A clínica foi bem avaliada tanto por alunos, quanto por supervisores. As experiências de estágios permitem uma formação mais centrada no modelo de competências e habilidades, formando um psicólogo capaz de intervir e atuar em situações-problema, de modo menos aplicador de conteúdos teóricos, o que não se sustenta mais perante as rápidas e complexas mudanças do mundo.

Entretanto, os diferentes atores institucionais indicaram haver dificuldade para que a formação ocorra calcada nesse modelo. Ainda não houve superação da cultura conteudista e a busca por uma especialização precoce, o que fortalece práticas formativas fragmentadas. Os estagiários se mostraram insatisfeitos com a escassez de comunicação e articulação: "aqui é cada um no seu quadrado, e isso prejudica muito o curso" (Estagiário). As supervisoras e a coordenação também disseram que se sentem realizando trabalhos "solitários", o que não se sustenta mais frente às demandas e os sintomas que têm chegado à clínica. Portanto, indicaram haver necessidade de mais comunicação, articulação e integração em diversos aspectos: entre os campos de atuação, entre a pluralidade de abordagens teóricas, na relação teoria e prática e no tripé ensino-pesquisa-extensão. A articulação com a rede pública de saúde apareceu como uma demanda recente, sendo hoje uma das principais.

\section{Considerações finais}

Em suma, a clínica-escola é um espaço vivo, de movimento, novidades imprevisíveis e intensidades de difícil captura. As diferenças e multiplicidades irrom- pem seu cotidiano a todo o momento. Mas em um mundo cada vez mais conectado e performático, um pensamento causal e linear e práticas fragmentadas prejudicam a formação, bem como o atendimento à comunidade. Frente às mudanças que estão ocorrendo, é necessário avançar com relação a esse modelo. Sabe-se que o processo é gradativo e lento, mas é necessário que isso seja problematizado. Uma frase que consta no projeto de implantação da sede da clínica caminha nesse sentido: "da associação ensino/extensão, da síntese entre a teoria e vivência profissional, surgirão, necessariamente, questionamentos, novas indagações, os quais hão de levar professores e alunos à produção e à renovação permanente de nossos conhecimentos" (Pontifícia Universidade Católica de Minas Gerais, 1989). Este estudo, ao mapear potências e desafios, aponta justamente para a necessidade de se repensar constantemente as práticas formativas do dispositivo analisado. Não se pode negligenciar o fato de que essas mudanças não dependem apenas da clínica-escola, mas demandam movimentos por parte da Universidade e da rede pública. Nem o fato de que a clínica-escola é atravessada por uma estrutura institucional que, por vezes, cria obstáculos para a efetivação de seus objetivos.

Acredita-se que o modelo de trabalho e de formação que a nova configuração social impôs representou um avanço com relação ao modelo anterior: conteudista, descontextualizado e com foco apenas no "como fazer". No entanto, esse modelo também traz consigo novos perigos, pois, como bem disse Deleuze ao falar sobre a sociedade de controle: "não se deve perguntar qual é o regime mais duro, ou o mais tolerável, pois é em cada um deles que se enfrentam as liberações e as sujeições" (Deleuze, 1992, p. 224). Ressalta-se a necessidade de que haja mais estudos que contemplem essa temática, ampliando a discussão para além da rasa crítica de que esse ainda é um modelo "neoliberal".

Ressalta-se também a importância de estudos que tratam do espaço das clínicas-escolas. Aqui focalizou-se a via da formação, ficando claro o quanto as transformações sociais apontam a necessidade de se repensar as práticas formativas. Mas este estudo abriu caminho para se mapear as práticas de uma clínica-escola no que tange a sua dimensão de prestação de serviço à comunidade, entendendo as demandas dos pacientes que chegam até lá, a fim de se repensar os serviços prestados para essa via. Ou seja, esta pesquisa não esgota, de modo algum, os estudos sobre esses espaços. 


\section{Referências}

Amaral, A. V., Luca, L., Rodrigues, T. C., Leite, C. A, Lopes, F. L, et al (2012). Serviços de psicologia em clínicas-escolas: Revisão de literatura. Boletim de Psicologia, 62(136), 37-52.

Araldi, E., Maraschin, C., \& Diehl, R. (2014). Por um modo mais incorporado de explicar o fazer do psicólogo. Psicologia ciência e profissão, 34(2), 420-443. https://doi.org/10.1590/1982-3703000292013

Arend, M. I., \& Motta, R. F (2014). Representação social da psicologia e do psicólogo na sala de espera de uma clínica-escola. Estudos em Psicologia, 31(3), 415-423. https://doi.org/10.1590/0103-166X2014000300010

Associação Brasileira de Ensino de Psicologia - Abepsi. (2013). Diretrizes curriculares. São Paulo, SP. Recuperado de http://www.abepsi.org.br/temas-e-debates/diretrizes-curriculares/

Becker, H. (1997). Métodos de pesquisa em ciências sociais. São Paulo, SP: Hucitec.

Bernardes, J. S. (2012). A formação em psicologia após 50 anos do primeiro currículo nacional da psicologia: Alguns desafios atuais. Psicologia Ciência e Profissão, 32, 216-231. https:// doi.org/10.1590/S1414-98932012000500016

Boeckel, M. G., Krug, J. S., Lahm, C. R., Ritter, F., Fontoura, L. O., et al. (2010). O papel do serviço-escola na consolidação do projeto pedagógico do curso de Psicologia. Psicologia Ensino \& Formação, 1(1), 41-52.

Conselho Federal de Psicologia - CFP (Org.) (2013). Carta de serviços sobre estágios e serviços-escola. Brasília, DF. Recuperado de http://site.cfp.org.br/publicacao/carta-de-servicos-sobre-estagios-e-servicos-escola/

Cury, B., \& Ferreira Neto, J. L. (2014). Do currículo mínimo às diretrizes curriculares: Os estágios na formação do psicólogo. Psicologia em Revista, 20(3), 494-512. https://doi.org/10.5752/P.1678-9523.2014V20N3P494

Deleuze, G. (1992). Conversações. (P. Pelbart, Trad.). Rio de Janeiro, RJ: 34.

Ferreira Neto, J. L. (2011). Psicologia, políticas públicas e o SUS. São Paulo, SP: Escuta.

Ferreira Neto, J. L. (2015). Pesquisa e metodologia em Michel Foucault. Psicologia: Teoria e Pesquisa, 31(3), 411-420. https://doi.org/10.1590/0102-377220150321914100420

Foucault, M. (2003). Estratégias, poder-saber: Ditos e escritos IV Estratégia, poder-saber. (V. Ribeiro, Trad.). Rio de Janeiro, RJ: Forense Universitária.

Foucault, M. (1979). Microfísica do poder (R. Machado, Trad.). Rio de Janeiro, RJ: Graal.

Flick, U. (2009). Qualidade na pesquisa qualitativa. Porto Alegre, RS. Artmed.

Honda, G., \&Yoshida, E. (2012). Mudança em pacientes de clínica-escola: Avaliação de resultados e processos. Paidéia, 22(51), 73-82. https://doi.org/10.1590/S0103-863X2012000100009

Lei No 9.394, de 20 de dezembro de 1996. Lei de diretrizes e bases da educação nacional. Diário Oficial da União, 23 dez. 1996.

Lima, V., \& Souza, R. (2014). Formação humana e competências: o debate nas diretrizes curriculares de psicologia. Psicologia e Sociedade, 26(3), 792-802. https://doi.org/10.1590/S0102-71822014000300027

Marturano, E. M., Silvares, E. F., \& Oliveira, M. S. (2014). Serviços-escola de psicologia: Seu lugar no circuito de permuta do conhecimento. Temas em Psicologia, 22(2), 457-470. https://doi.org/10.9788/TP2014.2-15

Nunes, E. (2010). A gramática política do Brasil (4a ed.). Rio de Janeiro, RJ: Garamond.

Oliveira, M. S., Pereira, R. F., Peixoto, A. A., Rocha, M. M., Oliveira-Monteiro, N. R., et al. (2014). Supervisão em serviços-escola de psicologia no Brasil: Perspectivas dos supervisores e estagiários. Psico, 45(2), 1-9. https://doi. org/10.15448/1980-8623.2014.2.15417

Parecer No 403, de 17 de dezembro de 1962. Dispõe sobre o currículo mínimo e duração do curso de psicologia. Diário Oficial da União, 19 de dezembro de 1962.

Parecer No CNE/CES 0062/2004, de 19 de fevereiro de 2004. Dispõe sobre as diretrizes curriculares nacionais para os cursos de graduação em psicologia. Diário Oficial da União,

Poelman, A. S., Bedran, P. M., Barroso, S. F., \& Lasmar, H. C. (2009). A clínica de psicologia: Unidade Coração Eucarístico. Psicologia em Revista, (ed. ouro), 41-52. 
Psicologia: Ciência e Profissão 2019, 39, e178561, 1-16.

Pontifícia Universidade Católica de Minas Gerais. (2003). Faculdade de Psicologia. Projeto político pedagógico do curso de psicologia da PUC Minas. Belo Horizonte, MG: o autor.

Pontifícia Universidade Católica de Minas Gerais. (1989). Projeto de implantação da clínica de psicologia da PUC Minas. Belo Horizonte, MG: o autor. Recuperado de http://wwwl.pucminas.br/documentos/clinica_psicologia_ projeto.pdf?PHPSESSID=7d8504af537dadefcc347b78ec0e2ab2

Seixas, P. S. (2014) A formação graduada em Psicologia no Brasil: Reflexão sobre os principais dilemas em um contexto pós DCN (Tese de Doutorado). Centro de Ciências Humanas, Letras e Artes, Universidade Federal do Rio Grande do Norte, Natal, RN, Brasil.

Yamamoto, O. H. (2012). 50 anos de profissão: Responsabilidade social ou projeto ético político? Psicologia Ciência e Profissão, 32, 6-17. https://doi.org/10.1590/S1414-98932012000500002

Zarifian, P. (2009). O modelo da competência: Trajetória histórica, desafios atuais e propostas. São Paulo, SP: Senac.

\section{Bárbara Morais Fam}

Psicóloga. Mestre em Psicologia pela Pontifícia Universidade Católica de Minas Gerais, Belo Horizonte - MG. Brasil. E-mail: barbaramfam@hotmail.com

(iD) https://orcid.org/0000-0002-7349-0253

João Leite Ferreira Neto

Professor no Programa de Pós-Graduação em Psicologia da Pontifícia Universidade Católica de Minas Gerais, bolsista de produtividade do CNPq. Belo Horizonte - MG. Brasil.

E-mail:jleite.bhe@terra.com.br

(iD) https://orcid.org/0000-0003-3900-508X

Endereço para envio de correspondência:

Av. Itaú, 525, Bairro Dom Cabral. CEP: 30535-012.

Belo Horizonte - MG. Brasil.

Recebido 14/04/2017

Reformulado 17/04/2018

Aceito 05/07/2018

Received 04/14/2017

Reformulated $04 / 17 / 2018$

Approved 07/05/2018

Recibido 14/04/2017

Reformulado 17/04/2018

Aceptado 05/07/2018

Como citar: Fam, B. M., \& Ferreira Neto, J. L. (2019). Análise das práticas de uma clínica-escola de Psicologia: Potências e desafios contemporâneos. Psicologia: Ciência e Profissão, 39, 1-16. https://doi.org/10.1590/1982-3703003178561

How to cite: Fam, B. M., \& Ferreira Neto, J. L. (2019). Analysis of practices of a Psychology training-clinic: Current potentials and challenges. Psicologia: Ciência e Profissão, 39, 1-16. https://doi.org/10.1590/1982-3703003178561

Cómo citar: Fam, B. M., \& Ferreira Neto, J. L. (2019). Análisis de las prácticas de una clínica-escuela de Psicología: Potencias y desafíos cotemporáneos. Psicologia: Ciência e Profissão, 39, 1-16. https://doi.org/10.1590/1982-3703003178561 